\title{
Optimization of the proximate ingredients of Rabri - An energy rich traditional Indian dairy product based on sensorial analysis
}

\author{
D.C. RAI, TANWEER ALAM AND AASTHA BHARDWAJ
}

\begin{abstract}
In this study, the effect of milk on the proximate composition of Rabri was done using three samples of milk obtained from cow, buffalo and mixed milks from both (50:50) and the Rabri samples were evaluated for their nutritional ingredients. The quality of Rabri produced from buffalo milk was found to be superior to Rabri produced from cow milk and their mixture. The composition of Rabri (from buffalo milk with $6 \%$ added sugar) was 34.49 per cent moisture, 20.33 per cent fat, 9.87 per cent protein, 30.93 per cent Lactose/sucrose, 2.14 per cent ash and 63.27 per cent total solids. The sensory evaluation of Rabri revealed that the average overall acceptability score for Rabri prepared from buffalo milk was highest (7.79) (on a 9-point hedonic scale) followed by mixed milk (7.71) with the least value obtained from cow milk (7.57).
\end{abstract}

KEY WORDS : Rabri, Sensory evaluation, Proximate analysis, Nutritional constituents

HOW TO CITE THIS PAPER : Rai, D.C., Alam, Tanweer and Bhardwaj, Aastha (2017). Optimization of the proximate ingredients of Rabri An energy rich traditional Indian dairy product based on sensorial analysis. Res. J. Animal Hus. \& Dairy Sci., 8(2) : 108-112 : DOI: 10.15740/ HAS/RJAHDS/8.2/108-112. 